\title{
Effect of Dietary Phenylalanine Restriction On Visual Attention Span In Mentally Retarded Subjects With Phenylketonuria
}

\author{
F. D. GIFFIN, J.T.R. CLARKE, and D. M. d'ENTREMONT
}

SUMMARY: An ABA within-subject study design was used to assess the effect of dietary phenylalanine restriction on the visual attention span of three mentally retarded males $(9,15$, and 21 years old) with phenylketonuria. Visual altention span was measured by recording the amount of time the subjects visually fixated pictures projected on a screen according to a standardized test protocol. After 4-6 weeks of baseline testing ( $A$-phase), each subject was placed on a phenylalaninerestricted diet, designed to maintain plasma phenylalanine levels at $0.3-0.9$ $m M$, for $8-14$ weeks (B-phase). A return to baseline phenylalanine intake (A-phase) was achieved by surreptitiously adding

RÉSUMÉ: Nous avons évalué l'effet d'une restriction diététique en phenylalanine sur la durée d'attention visuelle de trois patients mâles retardés mentalement $(9,15$ et $2 l$ ans) et atteints de phenylcetonurie. utilisant pour ce faire un programme $A B A$. La durée d'attention visuelle fut mesurée en enregistrant le temps pendant lequel les sujets fixaient une image projetée sur écran. suivant un protocole standardisé de tests. Après 4-6 semaines de tests de base (phase A), chaque sujet a reçu pendant 8-14 semaines (phase $B$ ) une diète restrictive en phenylalanine diète calculée de façon à maintenir un taux plasmatique de phenylalanine à $0.3-0.9 \mathrm{mM}$. Un retour au niveau de base d'ingestion de phenylalanine était effectué "sournoisement" en

From the Department of Pediatrics, The Atlantic Research Centre for Mental Retardation, Dalhousie University; and Department of Psychology, Izaak Walton Killam Hospital for Children, Halifax, Nova Scotia.

Reprint Requests to: Dr. J.T. R. Clarke, Department of Pediatrics, Clinical Research Centre, Room C-RI, Dalhousic University. Halifax. Nova Scotia B3H 4H7 Canada.

Some of the results reported here were presented at the annual meeting of the Canadian Society for Clinical Investigation. February 5. 1979, in Montreal (Clin. Res. 26: 872A, 1978). sufficient L-phenylalanine to the therapeutic diets to increase plasma concentrations of the amino acid to pretreatment levels. Diet treatment (B-phase) was associated with highly significant improvements in visual attention span in two subjects (multivariate analysis of variance, $P<<0.001$ ); the third subject, the most retarded, showed no effect. No objectively demonstrable change in behavior was documented in any subject. However, the results support the view that phenylalanine toxicity extends beyond early childhood and that some component of the toxicity is reversible, even in severely retarded patients with phenylketonuria.

ajoutant suffisamment de phenylalanine à la diète pour retourner le taux plasmatique à son niveau antérieur. La phase thérapeutique (phase B) fut associée d̀ des améliorations hautement significatives de la durée d'attention visuelle chez 2 sujets (analyse multivariée de variance, $p<0.001$ ); le troisième sujet, le plus retardé, n'a montré aucun effet. Aucune amélioration ne fut notée dans le comportement des sujets. Cependant ces résultats appuient l'hypothèse selon laquelle la toxicité de la phenylalanine transcende la période de l'enfance, et que certaines composantes de cette toxicité sont réversibles, même chez des patients pheny/cetonuriques sévèrement retardés.
Few dispute the benefit of wellregulated dietary phenylalanine restriction begun early in infancy in the treatment of classical phenylketonuria (PKU). However, there is less unanimity concerning the value of treatment later in childhood. In particular, whether the re-institution of phenylalanine restriction is associated with any improvement in the behavior or intelligence of mentally retarded persons with PKU is not clear. Estimates of mental capacity are unreliable in this type of patient, and the methods available for assessing changes are relatively insensitive. Some investigators have employed behavior scales to measure the effects of dietary and behavioral intervention in PKU (Frankenburg et al., 1973; Marholin et al., 1978), but the behaviors studied, such as aggression, are difficult to quantify and are subject to a variety of external influences that might prejudice their expression.

Since the performance of retarded patients with PKU is difficult to assess by conventional clinical procedures, we considered that some of the more recent methodological approaches employed in infant research might prove valuable in evaluating this group of patients. One such recently developed technique is the evaluation of preferential viewing or visual selectivity (Fantz, 1965). Miranda and his colleagues (1977) used this technique to test visual fixation responses of high-risk neonates and showed that the responses were a better predictor of mental performance than conventional clinical neurological examination. We developed a variation of the technique to evaluate visual attention span in retarded PKU patients. Specifically, we measured the percentage of time the patients visually fixated each of 
several presentations of a single visual stimulus (a picture projected on a screen) provided at repeated intervals under controlled conditions. We then assessed the effect of dietary phenylalanine restriction on the performance on the test of three mentally retarded young males with PKU. The results showed that in two cases, decreases in the plasma phenylalanine to less than $0.9 \mathrm{mM}$ were associated with significant increases in visual attention span.

\section{SUBJECTS AND METHODS}

\section{Subjects}

The subjects were three white males severely mentally retarded as a result of PKU. All were institutionalized in three different training centers for the mentally retarded.

S1, the 9-year-old boy, was first diagnosed with PKU at 8 months of age. Although placed on a lowphenylalanine diet at the time, regulation of the treatment was poor. By age 3 years, he was placed in an institution for the mentally retarded, where he remained. The institution staff continued to administer a modified low-phenylalanine diet, but periodic checks of plasma phenylalanine levels consistently showed concentrations above I $\mathrm{mM}$. This boy was the least retarded of the test group. He was toilet-trained and could feed himself. However, he had no intelligible speech and could not dress himself. Inspite of his mental handicap, he was described as pleasant and relatively easy to manage.

S2, a 21-year-old man, was found to have PKU at 13 months of age. He was treated with a low-phenylalanine diet until age 3 years 10 months. He was placed in an institution for the mentally retarded at 5 years of age. Unlike Sl, he exhibited highly disruptive, aggressive and hyperactive behavior, characterized in part by almost continuous compulsive stereotypic mannerisms. He was not toilettrained, but he could feed himself. He had no intelligible speech and could not dress himself. In an effort to control his behavior, he had been given pericyazine, $10 \mathrm{mg}$ twice daily, which he was receiving during the first 3-4 weeks of the study.
S3, a 15-year-old boy, was diagnosed with PKU at 5 years 3 months of age. He was institutionalized at that time and treated with a low-phenylalanine diet for 3 years. He was the most severely retarded of the group. He was highly aggressive and hyperactive. Although he was ambulatory, he was not toilet-trained and could not feed or dress himself. Like the others, he had no intelligible speech.

None of the subjects suffered from any recognized seizure disorder; all had apparently normal vision. Efforts to estimate IQ levels reliably by conventional methods were futile.

In each case, the respective institutions had requested advice concerning means to control the disruptive behavior of the subjects, thus initiating the opportunity to evaluate systematically the potential benefit of dietary phenylalanine restriction. The studies were carried out with the informed consent of the subjects' parents and the relevant adminstrative authorities.

\section{Testing procedure}

A small, dimly-lit room, free of extraneous stimuli, was used in each case to test visual attention. Slides were projected on a screen positioned $3.5 \mathrm{~m}$ from the subject's chair; the projected image subtended $4-6^{\circ}$ visual angle. The mean illumination of the image at the subject's viewing distance was $20.4 \mathrm{~cd} / \mathrm{m}^{2}$. A timer was used to control slide-on/slide-off alternating conditions for each slide presentation. The duration of on-target viewing was monitored by an observer equipped with a drum recorder revolving at a rate of $3 \mathrm{~mm} / \mathrm{sec}$. On the same recording, a second pen automatically recorded the slide-on/slide-off condition.

The subjects were tested separately in their own institutions. Each test consisted of four slide viewing sessions. During each session, the subject was shown 10 presentations of the same slide; each presentation was 14 sec. duration, and they were separated by intervals of $6 \mathrm{sec}$. during which the screen was lit but showed no picture. Sessions were separated by $2-5$ minute breaks. Four different slides ( 3 cartoons and a country scene) were used on each test day, one slide for each session of 10 presentations. A different set of slides with similar subject matter was used for each series of 4 sessions; however, the order of presentation of the slides was always the same: a cartoon followed by the country scene followed by the last two cartoons. All tests were conducted by the same observer. Visual fixation was monitored by watching the eyes of the subject.

\section{Study design}

A partially blind, within-subject (ABA) study design was employed. During the first 4-6 weeks (A-phase), baseline data were obtained. After 46 tests (16-24 sessions) had been completed, each subject was placed on an isocaloric low-phenylalanine diet, adequate to maintain plasma phenylalanine levels at $0.3-0.9 \mathrm{mM}$ for 8-14 weeks (B-phase). Although it was impossible to conceal this change from the institutional staff, the testerobserver was unaware of the initiation of the therapeutic diets. After 8-14 weeks of dietary phenylalanine restriction, sufficient L-phenylalanine was added surreptitiously to the diets (added to the low-phenylalanine milk substitute) to increase the amount ingested to at least $5 \mathrm{~g}$ per day. For this stage of the study (A-phase), only the directors of participating institutions and the study coordinators were aware when the high phenylalanine intake was resumed in each case. Throughout the study, plasma phenylalanine and tyrosine levels were measured by automatic amino acid analyzer (De Wolfe et al.; 1967) at weekly intervals on venous blood samples anticoagulated with heparin.

\section{Calculations and statistics}

Using the recordings from the drug recorder, the cumulated time the subjects each spent visually fixating the projected slide during each 14 second slide presentation was calculated and expressed as the percentage of the total time the slide was actually available for viewing. Overall variations were evaluated by a computerassisted multivariate analysis of variance employing Subprogram ANOVA of the Statistical Package for the Social Sciences (Nie et al., 1975). 


\section{RESULTS}

Although occasionally test sessions were disrupted by unruly behavior, with only a few exceptions at least two and usually four satisfactory sessions of ten 14 second slide presentations were successfully completed. After 27 days on a low-phenylalanine diet, S2 developed marked somnolence, and the pericyazine he was receiving was discontinued. He recovered rapidly once the drug was withdrawn. The same subject contracted a mild upper respiratory infection about 2 weeks later. This was accompanied by a sudden, though transient, elevation of his plasma phenylalanine level to $>1$ $\mathrm{mM}$ for about two weeks. Apart from this short episode of hyperphenylalaninemia, dietary phenylalanine restriction decreased plasma levels in all subjects to $0.3-0.9 \mathrm{mM}$ for $8-14$ weeks.

The results of visual attention during the baseline period (A-phase) revealed striking differences among the three subjects. SI, who was the least mentally handicapped, scored highest (43.8 $\pm 2.4 \%$ ); and S3, who was the most severely retarded of the three, scored the lowest $(1.6 \pm 1.0 \%)$.

Fig. 1 shows the effect of dietary phenylalanine restriction on the visual attention span of $\mathrm{S} 1$ and $\mathrm{S} 2$ over the entire course of the study. Both showed marked improvements during the period of phenylalanine restriction. The effect was reversed when plasma phenylalanine concentrations rose to pretreatment levels, even though the change in plasma levels of the amino acid in SI was relatively small. The results of multivariate analyses of variance indicated that the effects of the diet, allowing for the main effects and all two-way interactions of session, presentation and day of testing, were highly significant in both subjects ( $1: \mathrm{F}=32.7, \mathrm{df}=2$ and 453. $\mathrm{P}<<0.001 ; \mathrm{S} 2: \mathrm{F}=27.6, \mathrm{df}=2$ and 486, $P<<0.001$ ). While we chose 0.9 $\mathrm{mM}$ as the upper limit of an acceptable plasma phenylalanine concentration for the treatment of PKU, even at lower levels during the B-phase, visual attention span appeared to vary inversely and proportionately with the concentration of the amino acid (Fig. 1). In contrast to $S 1$ and $S 2, S 3$ showed no change in visual attention span during the course of the study.
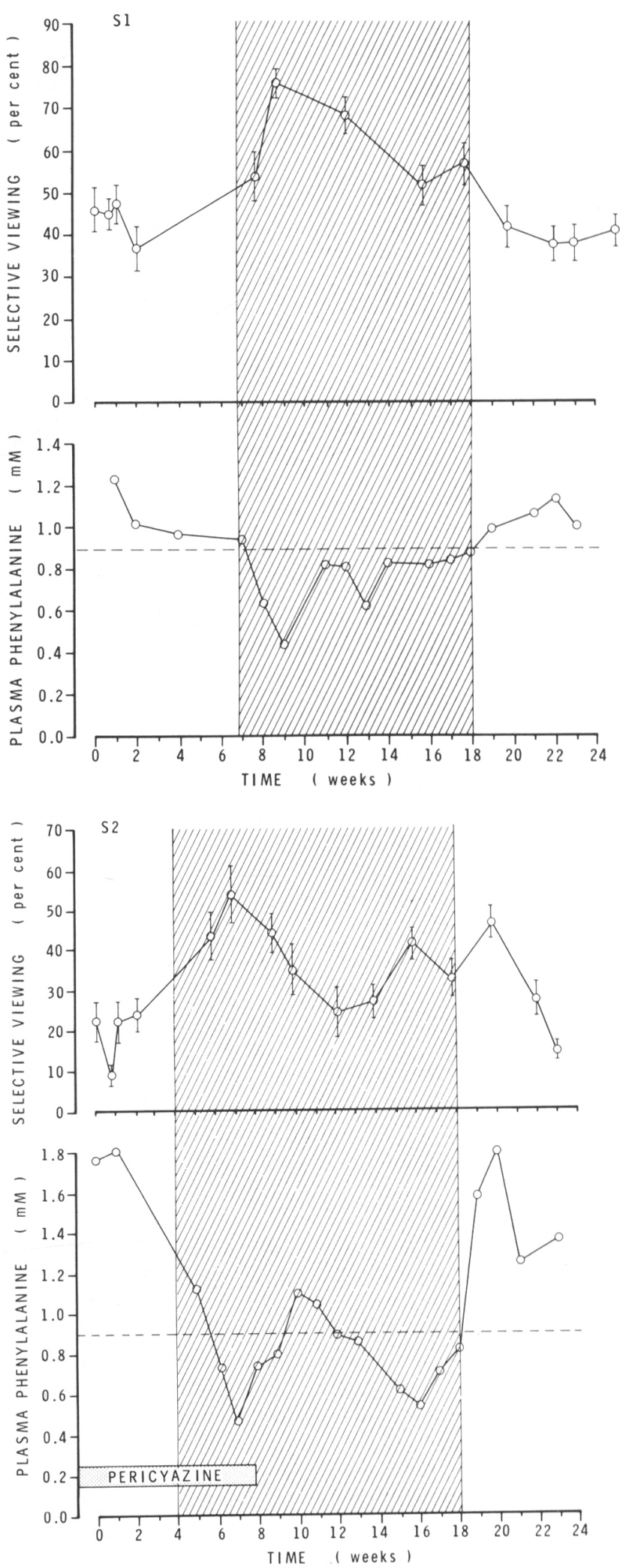

Figure $l$ Effect of dietary phenylalanine restriction on visual attention span of PKU subjects. The visual attention spans are shown as mean responses with the standard errors of the means indicated by brackets. The shaded area shows the period of dietary phenylalanine restriction. $S 1=$ first subject aged 9 yrs.; $S 2=$ second subject aged 21 years. 
No systematic change in behavior of SI was observed over the course of the study. On the other hand, the staff of the institution caring for $\mathbf{S} 2$ reported a decided improvement in his overall demeanour during the B-phase. He is claimed to have become more affectionate, easier to manage, and for the first time in his life, he became toilet trained. Although these positive behavior traits tended to regress when his plasma phenylalanine level rose to $>1$ $\mathrm{mM}$, the changes were not quantitated objectively. The possibility that the changes observed might be attributable to the withdrawal of the neuroleptic medication he received during the early stages of the study could not be eliminated.

Further analysis of the data showed that both $S 1$ and $S 2$ appeared to show a preference for the slides depicting country scenes as opposed to the cartoons. However, since the slides were always presented in the same order, whether this preference was due to some inherent quality of the stimulus, or the fact that it was always the second stimulus presented could not be determined. Both subjects also showed a gradually declining interest in each stimulus over the course of each session of 10 slide presentations. This trend was not influenced by dietary phenylalanine restriction.

\section{DISCUSSION}

The usual practice in the management of PKU is to prescribe closely regulated dietary phenylalanine restriction from the time of diagnosis in early infancy to 4-8 years of age. Treatment is then generally terminated or modified to permit ingestion of more protein-containing foods. This has been reported to produce no demonstrable ill effects (Horner et al., 1962; Kang et al., 1970; Holtzman et al., 1975; Koff et al., 1979); some workers have even suggested that termination of the therapeutic diet improved the behavior of some children with the disease (Solomons et al., 1966). On the other hand, other groups have reported deterioration of IQ (Bicket and Kaiser-Grubel, 1971; Brown and Warner, 1976; Smith et al., 1973) and behavior (Bruhl et al., 1965; Bentovim, 1968; Frankenburg et al., 1973) in children with PKU after returning to an unrestricted diet. Although some of the changes may be transitory (Frankenburg et al., 1973), the recently published results of a large collaborative European study suggest that the effects on intellectual progress may be lasting (Smith et al., 1978).

While a consensus may be emerging concerning the short- and long-term hazards of diet termination in older children with PKU, no such agreement seems to exist regarding the possible benefits of re-introducing phenylalanine restriction in mentally retarded patients later in childhood or as adults. Some workers have reported improvement of IQ, decreased hyperactivity and irritability, improved disposition, and improved alertness and attentiveness associated with the re-institution of low-phenylalanine diets (Bruhl et al., 1965; Anderson et al., 1976). On the other hand, Marholin and his colleagues (1978) recently reported that diet treatment produced few significant changes in the social behavior of six retarded adults with PKU, though two showed some amelioration of abnormal motor behavior.

In our study, we employed a technically simple test of visual attention to evaluate quantitatively the specific response to a standardized sensory stimulus. The baseline data (A-phase) were remarkably stable, and the scores of the three subjects correlated well with other indices of behavioral abilities in each case. Moreover, the pretreatment performance of the subjects seems to have been of some predictive value in determining the effectiveness of dietary phenylalanine restriction. The subject displaying the best pretreatment performance also had the most clear cut and beneficial response to treatment; the one with the poorest baseline performance showed no effect of treatment whatsoever. Thus, the assessment of visual attention span might prove useful in the first place in screening retarded persons with PKU to determine how they might respond to a return to a low-phenylalanine diet.

The effects of the low-phenylalanine diet on general social behavior were difficult to assess. Attempts to evaluate stereotyped behavior, impulsivity, hyperactivity, etc., failed to show any clearly demonstrable effects of diet. Although S2 appeared to show some improvement in behavior and training during dietary phenylalanine restriction, this could not be clearly dissociated from the effect of withdrawing the neuroleptic medication he was given in the early stages of the study.

Despite the absence of any measurable effect on general behavior, two of the subjects showed highly significant improvements in visual attention span while on low-phenylalanine diets. The results support the view that phenylalanine toxicity extends beyond early childhood. In addition, however, they also indicate that some of the toxic effects of the amino acid are at least partially reversible. While this has been recognized for many years in young children with PKU (Armstrong et al., 1957), our results show that it applies also for much older, severely retarded individuals with the disease. In the evaluation of potential benefits of dietary phenylalanine restriction in individual patients in this group, visual attention span appears to be more sensitive than other behavioral indices in the assessment of these particular effects. This is of considerable practical importance since most other behavioral indices are much more cumbersome and time-consuming to evaluate.

What the implications of our results are regarding the value of dietary phenylalanine restriction in the training and education of older children and adults with PKU is not entirely clear. Diet might be expected to be beneficial as an adjunct in the training of individuals already mentally handicapped as a result of PKU simply by virtue of its demonstrated effect on attention span. In addition, however, it is tempting to speculate that the apparent deterioration of IQ and the selective learning disabilities reported in some older PKU patients with normal intelligence might also be attributable to reversible effects of hyperphenylalaninemia and therefore be amenable to dietary treatment.

\section{ACKNOWLEDGEMENTS}

This study would not have been possible without the dedicated cooperation of the staffs of the Pictou Children's Training Centre in Pictou, Mountain View 
Home in Waterville and the Digby Children's Training Centre in Digby, Nova Scotia. Plasma phenylalanine and tyrosine levels were measured by Dr. M.S. DeWolfe, Halifax. We are indebted to Dr. J. B. Garner of the Department of Preventive Medicine, Dalhousie University, for assistance with the statistical analyses of the data. Dr. Wayne MacDonald, Department of Psychology, Izaak Walton Killam Hospital for Children, Halifax, provided valuable advice and criticism. Miss Eilene Hogan, nutritionist at the Izaak Walton Killam Hospital for Children, helped with the dietary management of the subjects. The project was supported in part by grants from Dalhousie University Faculty of Medicine, the Izaak Walton Killam Hospital for Children, and the governments of Nova Scotia. New Brunswick and Prince Edward Island.

\section{REFERENCES}

ANDERSON, V., SIEGEL, E. and BRUHL, H., (1976). Behavioral and biochemical correlates of diet change in phenylketonuria. Pediatr. Res., 10, 10-17.

ARMSTRONG, M.D., LOW, N.L. and BOSMA, J.F. (1957). Studies on phenylketonuria IX. Further observations on the effect of phenylalanine-restricted diet on patients with phenylketonuria. Am. J. Clin. Nutr., 5, 543-554.

BENTOVIM, A. (1968). Controlled observations of phenylketonuric children on and during withdrawal from low-phenylalanine diet. Arch. Dis. Child., 43, 745-746.

BICKEL, $H$. and GRUBEL-KAISER, S. (1971). Ober die Phenylketonurie. Dtsch.
Med. Wochenschr., 96, 1415-1423.

BROWN, E.S. and WARNER, R. (1976). Mental development of phenylketonuric children on or off diet after the age of six. Psychol. Med., 6, 287-296.

BRUHL, H., ARNESON, J. and BRUHL, M. (1965). Effect of a low-phenylalanine diet on older phenylketonuric patients. Am. J. Ment. Defic., 69, 225-235.

DeWOLFE, M.S., BASKURST, S. and COCHRANE, W. A. (1967). Automatic amino acid analysis of blood serum and plasma. Clin. Biochem. 1, 75-81.

FANTZ, R.L. (1965). Visual perception from birth as shown by pattern selectivity. Ann. N.Y. Acad. Sc., 118, 793-814.

FRANKENBURG, W.K., GOLDSTEIN, A. D. and OLSEN, C.D. (1973). Behavioral consequences of increased phenylalanine intake by phenylketonuric children: A pilot study describing a methodology. Am. J. Ment. Defic., 77, 524-532.

HOLTZMAN, N.A., WELCHER, D. W. and MELLITS, E.D. (1975). Termination of restricted diet in children with phenylketonuria: A randomized controlled study. New Engl. J. Med., 293, 1121-1124.

HORNER, F.A., STREAMER, C. W., ALEJANDRINO, L. L., REED, L. H. and IBBOTT, F. (1962). Termination of dietary treatment of phenylketonuria. New Engl. J. Med., 266, 79-81.

KANG, E.S., SOLLE, N.D. and PARK, S.G. (1970). Results of treatment and termination of the diet in phenylketonuria (PKU). Pediatrics, 46, 881-890.

KOFF, E., KAMMERER, B., BOYLE, P. and PUESCHEL, S. M. (1979). Intelligence and phenylketonuria: Effects of diet termination. J. Pediatr., 94, 534-537.

MARHOLIN, D., II, POHL, R.E., III, STEWART, R.M. TOUCHETTE, P.E., TOWNSEND, N.M. and KOLODNY, E. H. (1978). Effects of diet and behavior therapy on social and motor behavior of retarded phenylketonuric adults: An experimental analysis. Pediatr. Res., 12, 179-187.

MIRANDA, S. B., HACK, M.. FANTZ, R. L., FANAROFF, A.S. and KLAUS, M.H. (1977). Neonatal pattern vision: A predictor of future mental performance. J. Pediatr., 91, 642-647.

NIE, N.H., HULL, C.H., JENKINS, J.G., STEINBRENNER, $K$, and BENT, D. $H$. (1975). Statistical Package for the Social Sciences. Second Edition, pp. 410-421. McGraw-Hill, New York.

SMITH, I., LOBASCHER, M.E., STEVENSON, J.E., WOLFF. O. H., SCHMIDT, H. GRUBEL-KAISER, S. and BICKEL, $H$. (1978). Effect of stopping low-phenylalanine diet on intellectual progress of children with phenylketonuria. Br. Med. J., 2, 723-726.

SOLOMONS, G., KELESKE, $K$. and OPITZ, E. (1966). Evaluation of effects of termination of the diet on phenylketonuria. J. Pediatr., 69, 596-602. 